\title{
ECONOMICS OF ORGANIC RICE PRODUCTION
}

Raj K. Adhikari MSc (Ag. $)^{1}$

\begin{abstract}
Interest on organic agriculture is growing gradually in Nepal and the development interventions are concentrated more on technology generation and extension. But analysis on its economic aspect is lacking far behind. In order to know the economic performance of organic farming in general and that of organic rice production in particular, a survey research was carried out in Chitwan in 2010. From the study, the average productivity of organic rice production was found $3.15 \mathrm{Mt} / \mathrm{ha}$ which is consistent higher than national average. Among the factor cost, labor cost was found to contribute highest in total cost of production while poultry manure cost, human labor cost and oil cake cast were found to be significant factors at $(P$ value $<0.05)$ to contribute in total revenue. The $B: C$ ratio of organic rice production was found to be 1.15 .
\end{abstract}

Key words: B:C ratio, Cobb-Douglas function, cost, organic farming, rice, revenue

\section{INTRODUCTION}

Rice (Oryza sativa L.) stands first among the cereal crops in Nepal, which accounts for $50 \%$ of total edible cereal production and about 20\% to Agricultural Gross Domestic Product (AGDP) on the country (Bhujel and Ghimire, 2006) and provides more than $50 \%$ of the total calories required to the Nepalese people (Basnet, 2008). Also, in terms of area under cultivation rice comes first among the cereals which account about $50 \%$ of the total area under food crops of 3.2 million hectare (Joshi and Pandey, 2005). However, Nepal is a net food deficit country since 2005. The food produced in Nepal was sufficient to feed its population until 1990 but during 1990 to 1999, the domestic food production was not sufficient in Nepal. Again in 1999, cereal crop production boomed and fulfill the domestic demand but this condition do not prevail after 2005 (NPC, 2010).

To meet the demand for foods and vegetables, various types of pesticides and fertilizers are used in Nepal in an increasing trend. Department of Agriculture, Nepal has initiated the application of chemical pesticides for crop protection since 1960s (Aryal, 2006). Although, the national average of pesticide use $(142 \mathrm{gm} / \mathrm{ha})$ is comparatively lower than our neighboring countries (Diwakar et al., 2008) but location, dose, frequency, target crops, types and use practice of pesticides is more serious than anywhere (Diwakar et al., 2008; Koirala et al., 2009). The pesticide consumption is increasing by about $10-20 \%$ per year and pesticide expenses in market oriented production in Nepal is a major cost factor (Diwakar et al., 2008). On average, pesticide use results in a health cost of NPR 144 per farmer per year, which is nearly eight times higher than the health costs of people who do not use pesticides (SANDEE, 2008). Nepal imports seventy-three types of common pesticides in 342 trade names from six different countries with local production in scant quantity (Koirala et al., 2009). Study conducted during 1995-2004 revealed that out of 1034 sampled food products $12.1 \%$ were contaminated with pesticides (Koirala et. al., 2007). The huge numbers of pesticides are being used in number of crops ranging from kitchen garden to commercial farms. Of the total pesticide consumption in Nepal, about $40-50 \%$ is used in rice (MOAC, 2005).

Fertilizer is one of the prioritized inputs as mentioned in Agriculture Perspective Plan (APP) but total consumption has been far below the level as envisaged. Nepal has consumed 11,711 Mt of chemical fertilizer worth about NRs.226.8 million in the year 2003/04 (CBS,

\footnotetext{
${ }^{1}$ Market Development Specialist, Practical Action, Email: rajkadhikari@gmail.com
} 
2006). Although, the national average of the chemical fertilizer $(26 \mathrm{~kg} / \mathrm{ha}$ as of 2002$)$ consumption is low as compared to other SAARC countries (Pokhrel and Pant, 2009) but the amount of its use in commercial farms and pocket areas has exceeded to a maximum extent.

The problem of decreasing land fertility, use of high doses of inorganic fertilizer and increasing the cost of inorganic fertilizers are factors considered harmful for sustainability of production systems (K.C.et.al, 2004). Integration of legumes, green manuring and farm yard manures use in rice-based cropping systems can increase soil fertility (Watanabe and Lines, 1992; Bin, 1983) and yield higher than the conventional practices of using inorganic fertilizers (Tripathi and Suwal, 1999).

Considering the negative consequences of different agrochemicals in production, trading and consumption, organic agriculture is growing rapidly in the world. In Nepal also, organic agriculture is getting attention from farmers, government, and non-government organizations as well as market actors. Thus, the area and production and export volume of different commodities is increasing. As reported by International Federation of Organic Farming Movement (2006), the number of organic farms in Nepal is 1247, and the area under organic management is 1000 ha. If the area under traditional farming where farmers never used fertilizers and pesticides is considered, the area under organic farming should be much higher.

\section{OBJECTIVES}

Studies on organic farming practices are very limited in Nepal. Whatever studies have done are more concentrated on technical aspects only and economic aspect is lacking behind. Some research outputs are available on some cash crops but economic aspect of the major staple crop of Nepal i.e. rice is not available. Therefore, considering the need of such study, a primary level study on organic rice production was carried out during 2010 . The major objectives of the study were:

- to calculate the productivity, profitability and benefit cost ratio of organic rice farming

- to estimate the factor share in organic rice production in Chitwan, and

- to identify the marketing system and marketing channel of organic rice in Chitwan, Nepal of Calculate the Benefit Cost ratio in organic rice production in

\section{METHODOLOGY}

This study was mainly based on primary information collected from the farmers of Phoolbari VDC Chitwan district of Nepal in 2010. That VDC was purposively selected for the study due to availability of organic farmers. Sampling frame was prepared from the members directory of organic agriculture producers cooperative Limited, Chitwan. Out of the sampling frame, $25 \%$ of the household were taken as study sample for this study. Simple random sampling method was used to select the required number of sample. Thus, selected households were interviewed by using pre-tested semi-structured interview schedule.

The collected information were first tabulated, coded and entered into computer. All the local measurements were converted into standard unit and final analysis was done by using computer software packages: Microsoft Excel and Statistical Package for Social Science (SPSS).

\section{COST OF PRODUCTION}

Rice being a short duration crop, only the variable cost was considered to calculate the cost of production. The variable costs were the farm expenditure on seed, fertilizers, human labor, bullock labor, etc. Total cost of production was calculated by adding all the expenditure on variable inputs as below. 
Total cost $=\Sigma$ of cost of all variable inputs.

$=$ cost of land preparation + cost of fertilizer + cost of human labor + cost of other inputs

\section{GROSS MARGIN ANALYSIS}

The gross margin provides simple and quick method for analyzing farm business. For any enterprise, gross margin is the difference between the gross return and the total variable cost incurred.

Gross margin = Gross return - total variable cost Where,

$$
\begin{aligned}
\text { Gross return } & =\text { Eof gross returns } \\
& =\text { return from grain + return from straw }
\end{aligned}
$$

\section{BENEFIT COST RATIO ANALYSIS}

Benefit cost ratio is ratio between the gross return and total cost of any enterprise. In this study, benefit cost ratio was calculated by using the formula:

$$
B / C \text { ratio }=\frac{\text { Gross return }}{\text { Total } \cos t}
$$

\section{ANALYSIS OF FACTOR SHARE TO TOTAL OUTPUT}

Cobb-Douglas production function was used to estimate the elasticity of factors of production used in rice cultivation. The form of Cobb- Douglas production function was as follows:

$\mathrm{Y}=\mathrm{a} \mathrm{A}^{\mathrm{b} 1} \mathrm{~L}^{\mathrm{b} 2} \mathrm{~S}^{\mathrm{b} 3} \mathrm{~F}^{\mathrm{b} 4} \mathrm{P}^{\mathrm{b} 5} \mathrm{C}^{\mathrm{b} 6} \mathrm{H}^{\mathrm{b} 7} \mathrm{O}^{\mathrm{b} 8} \mathrm{e}^{\mathrm{u}} \quad$ Where, $\mathrm{Y}, \mathrm{L}, \mathrm{S}, \mathrm{F}, \mathrm{P}, \mathrm{C}, \mathrm{O}, \mathrm{H}$ are the values (in Rs.) of output, labor, seed, farm yard manure, poultry manure, oil cake, human labor and other. Variable ' $A$ ' is area (ha) and ' $u$ ' is a random disturbance term. The intercept has been denoted by ' $a$ ' and ' $b i$ ' is the slope coefficient of the associated variable, where $i=1 . . .8$. However, due to the problem of multicollinearity the land variable is dropped and all the values were converted into value term in per hector basis. Linear regression model was used after converting the value of variables into natural log.

\section{RESULTS AND DISCUSSIONS}

\section{CHARACTERISTIC OF FARMS AND FARMERS}

\section{Demographic characteristics}

The mean age of respondent was 44.85 years. Looking upon the gender of the respondents, $72 \%$ were the male. On cast basis, majority of the respondent were Brahmin (65\%) while Chhetri and Janajati were equal (15\% each). Regarding the education status of respondents, $55 \%$ of the respondents were having secondary education. Similarly, agriculture was found to be the major occupation for $82.5 \%$ of the respondents followed by service $(10 \%)$, business (5\%) and teaching $(2.5 \%)$. The detail of respondent characteristics is presented in table 1.

\section{Land holding}

The average land holding of the respondent was found to be 0.57 ha. On the basis of land holding, the respondents were categorized into 3 groups i.e. small $(<0.5 \mathrm{ha})$, medium $(0.5-1$ ha) and large ( $>1 \mathrm{ha})$. Out of the total respondents majority (55\%) were fall under medium land size category followed by small (40\%) and large (2\%). It signifies that majority of organic farmers are smallholder in nature. 
Table 1: Characteristics of respondents

\begin{tabular}{llrr}
\hline Parameter & Characteristics & Frequency & Percentage \\
\hline Gender & Female & 11 & 27.5 \\
& Male & 29 & 72.5 \\
Caste & Bhramin & 26 & 65.0 \\
& Chhetri & 6 & 15.0 \\
& Dalit & 2 & 5.0 \\
& Janajati & 6 & 15.0 \\
Education & College & 7 & 17.5 \\
& Illiterate & 3 & 7.5 \\
& Primary & 8 & 20.0 \\
& Secondary & 22 & 55.0 \\
Occupation & Agriculture & 33 & 82.5 \\
& Business & 2 & 5.0 \\
& Service & 4 & 10.0 \\
& Teacher & 1 & 2.5 \\
\hline
\end{tabular}

Source: Field Study, 2010

Table 2: Landholding size and frequency of respondents

\begin{tabular}{lrr}
\hline Category & Frequency & Percent \\
\hline Small $(<0.5 \mathrm{ha})$ & 16 & 40.0 \\
Medium $(0.5-1 \mathrm{ha})$ & 22 & 55.0 \\
Large $(>1 \mathrm{ha})$ & 2 & 5.0 \\
Total & 40 & 100.0 \\
\hline
\end{tabular}

Source: Field Studv. 2010

Table 3: Major source of information on organic farming

\begin{tabular}{lll}
\hline Source & Frequencies & $\begin{array}{l}\text { Percentage } \\
\text { s }\end{array}$ \\
\hline Training & 24 & 60 \\
Neighbor & 13 & 32.5 \\
Media (print and & 3 & 7.5 \\
electronic) & 40 & 100 \\
Total &
\end{tabular}

Source: Field Study, 2010

Table 4: Cost of production of organic rice

\begin{tabular}{lrrr}
\hline Items & Minimum & Maximum & \multicolumn{1}{c}{ Mean } \\
\hline Land preparation cost & 9166.67 & 26000.00 & 13809.26 \\
Seed cost & 1000.00 & 3545.45 & 1565.44 \\
Farm Yard Manure Cost & 225.00 & 37500.00 & 7496.40 \\
Poultry Manure Cost & 576.92 & 16500.00 & 3677.52 \\
Oil Cake Cost & 1.50 & 5000.00 & 1254.01 \\
Labor cost & 9900.00 & 20625.00 & 14280.90 \\
Other cost & 2500.00 & 6000.00 & 3975.62 \\
Total cost & 19485.00 & 74005.00 & 32249.91 \\
\hline
\end{tabular}

Source: Field Study, 2010 organic farming is profitable. From the study, the average $\mathrm{B}: \mathrm{C}$ ratio was found to be 1.15

\section{Cropping pattern}

Rice - vegetable - maize was the most prominent cropping pattern of the study area. However, following types of cropping pattern were also found in Chitawan district.

Rice - Vegetable - Vegetable

Rice - Vegetable - Maize

Rice - Wheat - fallow

Rice - Wheat - vegetable

Rice - fallow - Maize

Rice - fallow - fallow

Major source of information of organic production

For majority $(60 \%)$ of the respondent, training was the first major source of information about organic farming technology followed by neighbor (32.5\%) and media (7.5\%). Among the media, print media, mainly poster and booklets were the major sources.

\section{Return and Revenue analysis}

The study found that the average productivity of organic rice is 3.15 Mt/ha which is higher than national average productivity (2.90 Mt/ha) and, even higher average productivity of Terai belt of Nepal, i.e. $3.02 \mathrm{Mt} / \mathrm{ha}$. (MOAC, 2010). This proves that productivity in organic farming practices is not lower than non-organic practices.

Calculating the return from organic rice production, average total revenue is NRs. $66597.07 /$ ha that is accounted from grain (NRs. 56718.19/ha) and straw (NRs.9878.88/ha).

From the analysis minimum gross margin in organic rice production is NRs. $12995.00 /$ ha and maximum is NRs.58125.00/ha. The average gross margin is NRs. $34347.16 /$ ha. It indicates that 
which indicates that organic farming is profitable and the farmers are getting NRs. 1.15 in average over their investment of one rupees. The detail is presented in table 6.

Table 5: Return from organic rice production

\begin{tabular}{llll}
\hline Source & Minimum & Maximum & Mean \\
Grain revenue & 28421.05 & 75600.00 & 56718.19 \\
Straw revenue & 2812.50 & 18750.00 & 9878.88 \\
Total revenue & 40263.16 & 89250.00 & 66597.07 \\
\hline
\end{tabular}

Source: Field Study, 2010

Table 6: Gross margin and $\mathrm{B}: \mathrm{C}$ ratio

\begin{tabular}{lccc}
\hline Particulars & Minimum & Maximum & Mean \\
\hline Total cost & 19485.00 & 74005.00 & 32249.91 \\
Total revenue & 40263.16 & 89250.00 & 66597.07 \\
Gross margin & 12995.00 & 58125.00 & 34347.16 \\
B:C Ratio & .18 & 2.18 & 1.15
\end{tabular}

\section{FACTOR SHARES TO TOTAL REVENUE}

The Cobb Douglas production function model was found to be best fit since the F-ratio was highly significant (at $1 \%$ level of significance). The coefficient multiple determinations (R2) was found to be 0.606 which indicates that the $60.6 \%$ variation in the dependent variable was

described by the explanatory variables included in the model. It was found that only poultry manure, human labor costs and, oil cake cost have significant $(P$ value $<0.05)$ contribution to total revenue of organic rice production in Chitwan while seed and land preparation, farm yard manure costs were not found to be significant factors to contribute for total gross revenue. Interestingly, other cost was found to be negatively contributing factor but insignificant. The detail of contribution of different factors of production to the total revenue is presented in Table 17.

Table 7: Factors share to total revenue in organic rice cultivation

\begin{tabular}{lccccc}
\hline Variables & $\begin{array}{l}\text { Estimated } \\
\text { Coefficient }\end{array}$ & Std. Error & $\begin{array}{l}\text { Standardized } \\
\text { Coefficients }\end{array}$ & t-statistics & P-value \\
\hline Constant & 2.809 & 1.946 & & 1.444 & .159 \\
Log land preparation cost & .143 & .129 & .141 & 1.104 & .278 \\
Log seed cost & .170 & .107 & .186 & 1.590 & .122 \\
Log FYM cost & .065 & .040 & .232 & 1.615 & .116 \\
Log poultry manure cost & $.150^{*}$ & .044 & .437 & 3.376 & .002 \\
Log oil cake cost & $.021^{* *}$ & .009 & .276 & 2.380 & .023 \\
Log labor cost & $.538^{*}$ & .143 & .480 & 3.754 & .001 \\
Log other cost & -.159 & .173 & -.136 & -.919 & .365
\end{tabular}

Multiple R $=0.779, \mathrm{R} 2=0.606$, Adjusted R2 $=0.520$, F-ratio $=7.042^{*}$

${ }^{*}$ significant at $1 \%$ level of significance, ${ }^{* *}$ significant at $5 \%$ level of significance

MARKETING

The marketing system of organic rice in Chitwan was found to follow both conventional inorganic channel as well as new organic one. After a long effort, the farmers became to sell some of their produce through organic market outlets of different major cities; however still majority of the production is entered into conventional market. This study found that on an average, only about $30 \%$ of total organic production was marketed through organic channel.

In organic system, it is found that the organic rice (and other agriculture products also) is directly sold to the cooperative. The cooperative collects the demand from different traders and accordingly collect the product form individual farmers. In most cases, the cooperative collect the product from individual farmers and process it in its own processing unit (milling center) but sometimes it ask the farmers to prepare the final product as per 
demand received from trader. Then only the product is sold to different traders and ultimately reached to consumers. One of the most important things is that when the produce is sold through organic channel, farmers were getting Rs.2/kg higher than price in conventional market.

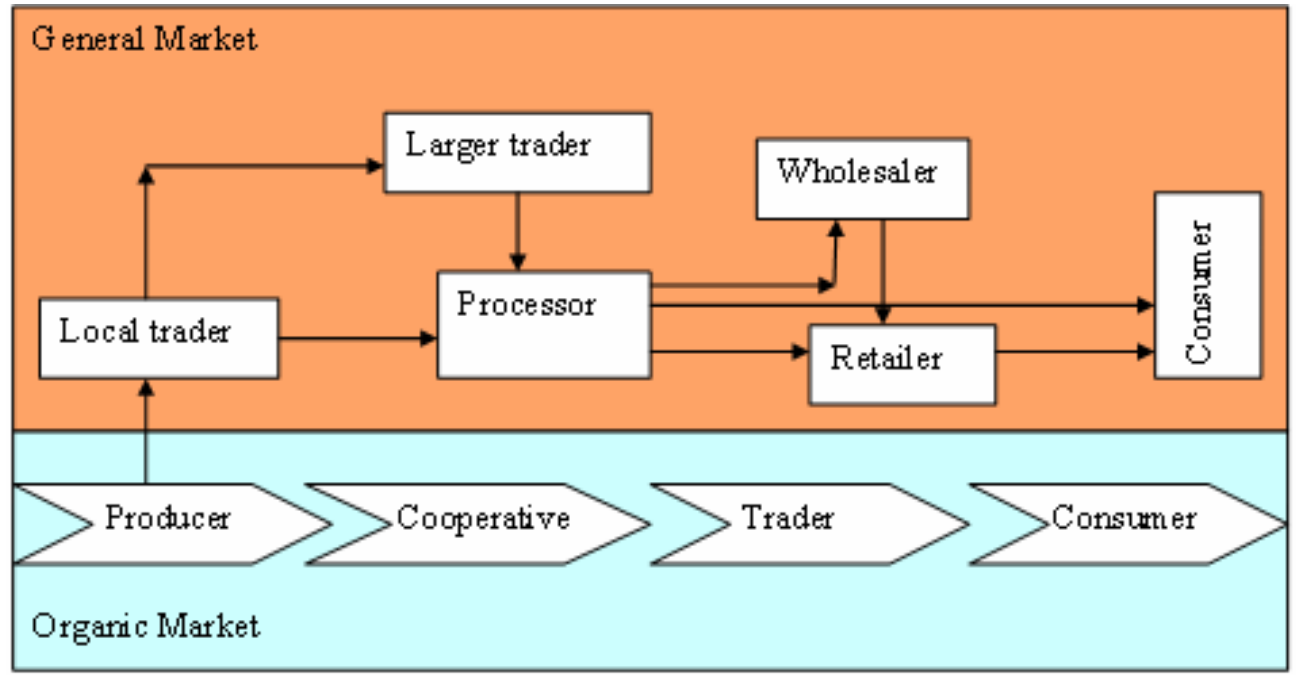

Fig.1: Marketing channel of organic rice in Chitwan

\section{CONCLUSIONS}

Most of the development agencies and agriculturist put their opinion on organic farming incurs high cost of production and couldn't meet the global food hunger. But, this study revealed that organic farming is more cost effective than conventional one and, can yield higher than the average. The higher productivity of organic rice than the national and regional average proved that the organic rice production is a viable option for the sustainable food production and food security. In spite of no significantly differentiated organic market for organic commodities, the enterprise is profitable. It indicates, if the separate market system could be established, this sector can support more in poverty reduction.

\section{ACKNOWLEDGEMENT}

I would like to acknowledge the entire farm households of the study site for their cooperation in field study. Organic Agriculture Producers Cooperative personals are highly acknowledged for providing relevant information.

\section{REFERENCES}

Aryal, S.B., 2006. Concept, Status, Prospects and Opportunities of Organic Farming in Nepal. Proceedings of a First National Workshop on Organic Farming 12-14 June 2006. Directorate of Agriculture Extension, Hariharbhawan, Lalitpur

Basnet, B.M.S., 2008. Environment Friendly Technologies for Increasing Rice Productivity. The Journal of Agriculture and Environment. 9:34-40

Bhujel, R.B. and S.P. Ghimire, 2006. Estimation of Production Function of Hiunde (Boro) Rice. Nepal Agric. Res. Journal.7:88-97

Bin, J., 1983. Utilization of green manure for raising soil productivity in China. Soil Sci. 135:65-69. 
CBS, 2006. Statistical Pockets Book of Nepal. Central Bureau of Statistics Kathmandu, Nepal.

Diwakar J., T. Prasai, S.R. Pant and B.L. Jayana, 2008. Study on major pesticides and fertilizers used in Nepal Scientific World. 6(6): 76-80

Joshi, P. and S. Pandey, 2005. Effects of Farmers' Perception on the adoption of modern rice varieties in Nepal. Deutscher Tropentag 2005, Conference on International Agriculture Research for Development, Stuttgart-Hohenheim, October 11-13, 2005

K.C. Ram B., B.B. Khatri, R. Mishra and B.K. Joshi, 2004. Agronomic performance of rice and potato in different cropping pattern. Nepal Agric.Res.Journal. 5:1-4

Koirala, P., D.B. Khadka and A. Mishra, 2007. Pesticide Residues as Environmental Contamination in Foods in Nepal. The Journal of Agriculture and Environment. 8:96-100

Koirala, P., S. Dhakal and A.S. Tamrakar, 2009. Pesticide Application and Food Safety Issue in Nepal. The Journal of Agriculture and Environment. 10:111-114

MOAC, 2005. Statistical Information On Nepalese Agriculture. Agribusiness Promotion and Statistics Division, Singha Darabar, Kathmandu, Nepal.

NPC, 2010. The Food Security Atlas of Nepal. Food Security Monitoring Task Force, National Planning Commission, Government of Nepal

Pokhrel, D.M. and K.P. Pant, 2009. Perspective of organic agriculture and policy concern in Nepal. The Journal of Agriculture and Environment 10: 89-99

PPD, 2007. Annual progress report. Plant Protection Directorate. Harihar Bhawan, Lalitpur, Nepal.

SANDEE, 2008. SANDEE Policy Brief, 27(08), January 2008

Tripathi, B.P. and B.N. Suwal, 1999. Effect of organic and inorganic fertilizers on rice and wheat yields and soil properties in rice-wheat system in rain fed lowland ecosystem. Nepal Agric. Res. Journal 3:89-93.

Watanabe, L. and C.C. Lines, 1992. Improving nitrogen fixing systems and integrating them into sustainable rice farming. Plant and Soil 141:57-67. 